\title{
Research Paper: Development of Screening Test Battery for Volleyball Players: A Mixed Method Study
}

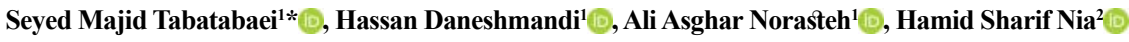

1. Department of Sports Injuries and Corrective Exercises, Faculty of Physical Education, University of Guilan, Rasht, Iran 2. Department of Nursing, School of Nursing and Midwifery-Amol, Mazandaran University of Medical Sciences, Sari, Iran.

\begin{tabular}{|c|c|}
\hline $\begin{array}{l}\text { Use your device to scan } \\
\text { and read the article online }\end{array}$ & Cofter Tahatabaei SM Daneshmandi H Norasteh AA SharifNia H Develonment of Screening Test Battery for Vollevball \\
\hline 口ritha & Players: A Mixed Method Study. Physical Treatments. 2017; 7(3):163-174. http://dx.doi.org/10.32598/ptj.7.3.163 \\
\hline atoph & doi": http://dx.doi.org/10.32598/ptj.7.3.163 \\
\hline
\end{tabular}

Funding: See Page 173

(c) Copyright: The Author(s)

Article info:

Received: 15 Mar 2017

Accepted: 25 Jul 2017

Available Online: 01 Oct 2017
Keywords:

Volleyball, Functional movement screening, Mixed method study, Validity, Reliability

\begin{abstract}
A B S T R A C T
Purpose: Design and development of functional movement screening in athletes are one of the important measures taken for reducing the injury in professional sports. Today, functional movement screening aimed at identifying athletes susceptible to injury is designed and implemented based on fundamental functional patterns and the performance of that particular sport. Currently, there are no standard protocols for the screening of volleyball-specific performance movements.
\end{abstract}

Methods: In this study, 20 volleyball high level experts were selected through purposive sampling method. The study data were collected by semi-structured interviews and field notes in 2017. The interview transcripts were encoded using MAXQDA V. 10 software. To extract categories and subjects, the thematic analysis approach was used. The results of interviews were conducted in a questionnaire to determine the validity and reliability was investigated. Face validity, content validity and construct validity (convergent and divergent validity) of the questionnaire was evaluated, too. The reliability was estimated by a test-retest method of 2 weeks interval using the intraclass correlation coefficient.

Results: In first analysis process, initial codes were extracted and then, 38 (out of the 82 existing potential tests) tests were identified. Finally, after proper examining of the validity and reliability of the tests, 12 tests including deep squat, inline lunge, trunk stability push up, rotary stability, shoulder mobility, triple hop for distance, hexagon, lateral lunge, triple jump for distance, sidearm medicine ball throw, closed kinetic chain upper extremity, and squat jump were identified for inclusion in screening test battery.

Conclusion: Based on the results of the interviews, the interviewees' choices are more based on the similarity of the tests with the movement patterns and performance capabilities in volleyball and considering the anatomical areas prone to injury. More prospective and follow up studies with various volleyball players are needed to show the capability of these tests to predict injuries.

\section{* Corresponding Author:}

Seyed Majid Tabatabaei, PhD Candidate

Address: Department of Sports Injuries and Corrective Exercises, Faculty of Physical Education, University of Guilan, Rasht, Iran.

Phone: +98 (918) 9915094

E-mail: majid.tabatabaea@yahoo.com 


\section{Introduction}

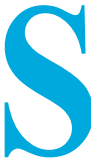

creening tools to identify risk factors and to develop injury prevention strategies have always been interesting topics for research. Screenings are conducted for various purposes, including the prevention of athletes' injuries [1]. In order to prevent injury, it is very important to know epidemiology and potential risk factors of injury. By reviewing the literature, we can find variables such as gender and previous injuries as intrinsic risk factors and level of play and technique as extrinsic risk factors for sport injury. In general, researchers consider factors such as warming up, cooling down, balance, flexibility, muscle imbalances, and sports environmental conditions as potential risk factors [2].

Screening can be used to help prevent injury through identifying limitations and functional impairments associated with the interested exercise $[3,4]$. The screening process takes place in many developed countries in pre-season trainings time $[5,6]$. Pre-season information is important for identifying athletes who are at risk of injury. Functional screening is an important tool for predicting and systematically examining injuries in various sports [7].

In this regard, Dallinga et al. (2012) reviewed the screening tools used as predictors of injury in various sports. This review study was conducted on team sports. They believed that the development of screening tools could help predict injury. Their findings show that most screening tools are used to predict a specific type of injury, such as Anterior Cruciate Ligament (ACL) injuries, ankle sprain and hamstring injuries, so that a set of different injuries in a specific sport discipline is examined. The tests used to predict these injuries were extracted by Dallinga et al. and classified in sets of anthropometric, flexibility, range of motion, and balance tests. Each of these classes cover some of the functional tests, not all of them. Combining these tests and information of injury epidemiology associated with a particular sport can contribute to the development of functional screening tools [7].

The literature on the screening of functional movements reveals that this tool has been developed in some sports such as football [8], gymnastics [9], Australian football [10], and dance [11]. In 2012, a tool was designed to functionally assess gymnast preparation under the name GFMT (Gymnastic Functional Measurement Tool) by Sleeper et al. using tests specific for gymnastics. This tool integrates variables of flexibility, speed, strength, endurance and balance and experts has confirmed it in this field. Their specific tests included rope climb test, jump test, hanging pikes test, shoulder flexibility test, agility test, over-grip pull-up test, splits test, pushup test, 20 yards sprint test, and handstand test. In their further research, Sleeper et al. examined normative value and validity of the GFMT tool by studying 105 gymnasts aged 6 to 18 years.

Overall, the GFMT had a high validity; however, this tool was unable to determine the severity of injuries and only revealed functional impairment. Anyhow researchers considered this recent finding as an advancement in the field of screening [9]. The methodology of Sleeper et al. in gymnastics can be used as a guide and basis for the development of screening tools in various sports. Moreover, the experience of the elite athletes in that particular field as well as the gathering of enough evidence in the literature would be useful, too.

Volleyball, like any other sport, associates with injury during the tournament and pre-season trainings. Because the volleyball playground is separated by a net, there is almost no possibility of contact between players of two teams. Therefore, it is believed that the likelihood of injury in this sport is lower than other sports, and in particular contact sports such as football and basketball [12]. However, collisions occur during attack and defense of net between players of two teams. Other risk factors for injury in this sport include landings and high jumps during spikes and attack block and diving when receiving in back court [13].

According to research results, the prevalence of injury in this sport is between 1.7 and 4.2 injuries per 1000 hours of play [12]. Although all injuries cannot be prevented, athletic performance can be improved by preventing even one injury. Recently, physiotherapists use functional movement tests, and especially Functional Movement Screening (FMS) as a screening tool in order to predict injuries, followed by the development of preventive strategies. Gary Cook et al. developed FMS for the first time so as to identify those with compensatory movement patterns in their kinetic chains. This screening tool consisted of seven movement tests that require balancing between mobility and stability. These tests include movement patterns of deep squat, hurdle step, inline lunge, shoulder mobility, active straight leg raise, trunk stability push up, and rotary stability [14].

The FMS is designed for all healthy people, not only sport populations, and some sports-specific components have been ignored. It seems that speed is the component which FMS has missed. High-speed movements that are an inseparable and inherent component in every sport are ignored in these 7 tests. Therefore, the FMS cannot pro- 
vide the full range of sport-induced motor patterns [15]. This subject became somewhat evident by Parchmann and McBride (2011), who compared the FMS and back squat with a maximum repetition, and the relationship between these two, with a speed of $20.10 \mathrm{~m}$, a high jump, and T-test of agility on 25 National Collegiate Athletic Association (NCAA) golfers.

By demonstrating a lack of correlation between the FMS and these performance tests, they confirmed that the FMS had limited ability to predict physical performance, acceleration, strength, and agility, especially when comparing with the lower extremity strength [16]. Ignoring deceleration variables and eccentric forces that are potential risk factors for injury are evident in these tests. Thus, it seems reasonable to use tests that can assess speed component and also be able to identify potential risk factors for the evaluation of functional movements of athletes. This can be a good complement to the FMS.

Schneiders et al. (2011) emphasized that the assessment of basic movements, through a functional approach should focus more on balanced exercise patterns rather than solely on the assessment of specific isolated joints or muscles [3]. Earlier in 2000, Rosch had emphasized the importance of this issue by suggesting that functional tests require design based on the performance and skill of players [17]. The assessment should in fact be done in such a way that all interested physical aspects be covered. Physical function consists of many components. These components may require assessment of balance, proprioception, muscle strength, muscle endurance, power, speed, agility, aerobic and anaerobic preparation, flexibility, muscle length tests, and functional movement patterns. However, depending on the subjects' needs and the target population, the scope of comprehensiveness for these tests may vary. For example, in some cases, subjects may not need evaluation of the balance and proprioception, and the flexibility tests maybe more important to them. Particularly for volleyball players, this may include flexibility, balance, power, agility, anaerobic fitness, action and reaction time. Testing battery should also be able to observe the progress of the rehabilitation programs for injured athletes [18].

After reviewing the validity and reliability of the functional movement screening tool designed by Cook et al. one can conclude that there is little reasonable evidence indicating strong support for FMS validity and reliability in sport as predictive tool for injury. Elizabeth et al. (2013) examined the reliability of the FMS test on elite ice hockey players. They concluded that the FMS is a test for baseball players, but further research has to be done to assess the predictability of injury of this tool [19].

Hither et al. (2014) studied the intra-rater reliability of FMS by raters at different experimental levels. Their subjects included 20 healthy students, who were tested by 3 beginner evaluators and 3 elite evaluators using FMS video recording. Their results showed that FMS scores were similar between evaluators with each experimental level. However, they acknowledged that elite raters better interpreted the results of the test compared to the beginner raters [20].

Schultz et al. (2013) examined the test-retest (intra-rater reliability) and inter-rater reliability of FMS on female athletes. Their results indicate an acceptable retest reliability. Excellent reliability was also observed between live evaluation and video-based evaluation. However, they reported a poor intra-rater reliability [21]. It seems that the FMS designed by Cook et al. still needs to be scrutinized and carefully tested for reliability and validity. Because FMS cannot completely represent the movement patterns of sports, its validity, reliability and injury prediction in sport populations is still ambiguous.

Thus the researcher has attempted to develop a functional performance screening tool through interviewing the experts in this field. This tool should have the ability to predict injuries in volleyball sports. Then the researcher evaluated the validity and reliability in the form of a questionnaire. For this purpose, by reviewing the literature of the background and taking into account the prevalence of epidemiology, movement patterns, and functional and skill needs of volleyball players, a questionnaire consisting of 82 tests in six categories of functional, agility, aerobic, anaerobic, muscle length and anthropometric was designed and initial tests were extracted through interview with volleyball specialists such as coaches, physicians and physiotherapists to be placed in the tool. In the following, the final tool was developed through examining the validity and reliability of these tests in the form of a questionnaire.

\section{Materials and Methods}

In the first step, the qualitative stage of study, 20 volleyball high-level experts including coaches, instructors, and sports physiotherapists were selected through purposive sampling method. The number of interviewees (sample size) depended on the theoretical saturation of the questions [22]. In this study, the required data were saturated after 20 interviews, so the interview process 
ended. Individual semi-structured interviews were conducted to collect the data.

Analysis of the data collected from each interview directed the next interview. The sampling continued up to the data saturation. Each interview lasted 60-120 min, with an average of $80 \mathrm{~min}$. The data were collected in 2017 . After collecting data, each interview was transcribed after recording. Each copy was imported into MAXQDA. The transcripts were coded and compared. In the next step, they were classified into categories and finally the items were extracted. The items were presented to experts and volleyball players in the form of a questionnaire so as to assess the validity and reliability of the items.

\section{Validity}

\section{Face validity}

Face validity was evaluated qualitatively and quantitatively. To assess qualitative face validity, 10 volleyball players were asked to comment on the level of difficulty, proportionality and ambiguity of the questionnaire items. In the next step, each item was evaluated quantitatively to determine its significance. To this end, 10 volleyball players responded the items based on a 5-point Likert scale from 5 (absolutely significant) to 1 (not at all significant). Then the effect score of the item was calculated based on the following formula [23].

\section{Effect score $=$ Frequency $(\%) \times$ Importance}

The frequency in percentage means the number of people giving each item a score of 4 or 5 points, and the importance, is the mean of the data scores given to each item. If the effect score becomes more than 1.5, then the item is very importance [24].

\section{Content validity}

Content validity was also examined qualitatively and quantitatively by the experts. To assess qualitative content validity during an interview with experts, the questionnaire was evaluated in terms of grammar, use of proper words, importance, representation and positioning of the items in their proper place and the time of completion of the designed tool. Subsequently, the content validity was quantitatively evaluated according to 10 experts' comments and by calculating the two properties of Content Validity Ratio (CVR) and Content Validity Index (CVI). CVR is used to ensure that the most relevant content is selected and CVI is used to ensure that the tool items are designed to best measure the content [23]. To calculate CVI, the following formula was used.

\section{Construct validity}

To evaluate the construct validity through Exploratory Factor Analysis (EFA), the items based on the 5-point Likert scale (strongly disagree - disagree - indifferent agree - strongly agree), along with the executive instruction of the test were given to the 217 volleyball players, including 184 men and 33 women aged 19 to 36 years. The Kaiser-Meyer-Olkin index and the Bartlett coefficient were calculated. KMO 0.7-0.8 was considered to be good and $0.8-0.9$ was considered strong. Then extraction of the factors was done by means of estimating the maximum likelihood using the varimax rotation.

The extracted factors were investigated using Confirmatory Factor Analysis (CFA) and the most common Goodness of Fit indices of the proposed model based on the acceptable threshold using the maximum likelihood estimation by SPSS-AMOS V. 22. According to the recommendations of Jaccard and Wan (1996), as well as Meyers et al. (2016), the Chi-square Goodness of Fit (CMIN), the Root Mean Square Error of Approximation, the Comparative Fit Index, the Normed Fit Index, the Adjusted Goodness of Fit Index, and finally, the Chi-square on the Degree of Freedom (CMIN/DF) were investigated $[25,26]$.

\section{Reliability}

At first, the reliability was evaluated by a test-retest method. Twenty volleyball players filled the questionnaire within two weeks, and then the scores obtained in these two phases were analyzed using Intraclass Correlation Coefficient (ICC). Then ICC was estimated with a two-way mixed effect model with a confidence interval of $95 \%$. The Standard Error of Measurement (SEM) was then evaluated using the formula. The internal consistency of the structure was accomplished by Omega McDonald's assessment. Finally, with the help of the CFA, the construct stability was calculated $[27,28]$. In other words, construct stability or factor stability is considered as a kind of alternative for the Cronbach $\alpha$ coefficient in the structural equation modeling, where in the present study, construct stability of greater than 0.7 was considered to be acceptable [29].

\section{Normal distribution, outliers, and missing values}

The normal distribution of data and the evaluation of outliers were evaluated in both single and multiple variables. The normal distribution of the univariate was 
evaluated with the help of the index of skewness $( \pm 3)$ and kurtosis $( \pm 7)$ and multivariate using the coefficient of Mardia $<0.0001$ [30]. On the other hand, single-variable outliers were evaluated using descriptive indices and multivariate outliers using Mahalanobis coefficient. At first, the percentage of missing values were calculated and eventually analysis was done by replacing with the help of the mean of the responsiveness.

\section{Results}

The contents of the interviews were analyzed for determining the items which were suitable to be included in the screening tool. In this analysis, the initial codes were identified and finally out of 82 existing potential tests, 38 tests were extracted. Table 1 shows the list of the extracted codes in the analysis. After performing the process, thirty-eight sub-items were identified for the six main items. In the following, the validity and reliability of the questionnaires were examined.

\section{Validity}

\section{Qualitative face validity}

The result show that, from the viewpoint of interviewees, all 38 items were clear, legible, simple and understandable in terms of content.

\section{Quantitative face validity}

Regarding the results obtained from the calculation of the quantitative face validity, all the items had an effect score of more than 1.5.

\section{Content validity ratio}

According to the results obtained from calculating the content validity ratio for the sub-items and its comparison with the values obtained by Lawshe [31], 19 tests of deep squat tests, triple hop for distance, hexagon, inline lunge, lateral lunge, rotary stability, vertical jump, trunk stability pushup, shoulder mobility, single leg landing, active straight leg raise, upper extremity closed kinetic chain, backward overhead medicine ball throw, sidearm medicine ball throw, triple jump for distance, jump squat, lumbar erector spinae, quadratus lumbarum assessment and Thomas had a content validity ratio higher than 0.62 , and the remaining tests did not have content validity, so they were deleted.

\section{Content validity index}

The results obtained for CVI can be found in Table 2.

\section{Construct validity}

Mean \pm SD values of age (y), height $(\mathrm{cm})$, weight $(\mathrm{kg})$, weekly practice $(\mathrm{h})$ and playing history of volleyball players were $26.1 \pm 3.0,188.0 \pm 5.8,87.9 \pm 6.1,9.6 \pm 2.0$, and $12.4 \pm 2.6$, respectively. The frequency distribution of volleyball players is also presented in Table 3 based on gender, dominant foot, dominant hand, level of competition, injury history and positions. The KMO was 0.795 and the Bartlett test was $1329.498(\mathrm{P}<0.001)$. The results of the EFA showed that the three latent factors (Figure 1) were $4.097,2.952$, and 1.163 . In total, the three extracted factors explained $45.91 \%$ of the total variance of the functional movement screening tool (Table 4). Then,

Table 1. List of extracted codes after analyzing the interviews

\begin{tabular}{|c|c|}
\hline Main Item & Sub-Item \\
\hline Functional tests & $\begin{array}{c}\text { Deep squat, Functional reach, Single leg squat, Triple hop for distance, } \\
\text { Hexagon, Inline lunge-Trunk stability push up, Y balance, Star excursion } \\
\text { balance, Multiple single leg hop stabilization, Rotary stability, Vertical } \\
\text { jump, Carioca drill, Lateral lunge, Timed sit up, Supine bridge, Shoulder } \\
\text { mobility, Active knee extension, Four square step, Endurance of lateral } \\
\text { flexors, Single leg landing, Active straight leg raise, Triple jump for } \\
\text { distance, Backward overhead medicine ball throw, Sidearm medicine ball } \\
\text { throw, Closed kinetic chain upper extremity }\end{array}$ \\
\hline Agility tests & T test, Illinois, Zigzag run \\
\hline Anaerobic tests & Jump squat \\
\hline Aerobic test & None \\
\hline Muscle length tests & $\begin{array}{l}\text { Lumbar erector spinae assessment, Quadratus lumbarum assessment, } \\
\text { Thomas test, Pectoralis major assessment, Pectoralis minor assessment, } \\
\text { Latissimus dorsi assessment }\end{array}$ \\
\hline Anthropometric tests & Arm span, Arm reach \\
\hline
\end{tabular}


Table 2. Results of computing CVR and CVI

\begin{tabular}{|c|c|c|}
\hline Sub Item & CVR & CVI \\
\hline Deep squat & 0.80 & 0.100 \\
\hline Functional reach & 0.40 & 0.70 \\
\hline Single leg squat & 0.40 & 0.60 \\
\hline Triple hop for distance & 0.70 & 0.80 \\
\hline Hexagon & 0.80 & 0.100 \\
\hline Inline lunge & 0.80 & 0.100 \\
\hline Y balance test & 0.30 & 0.70 \\
\hline Star excursion balance test & 0.40 & 0.70 \\
\hline Lateral lunge & 0.70 & 0.80 \\
\hline Multiple single leg hop stabilization & 0.30 & 0.50 \\
\hline Rotary stability & 0.80 & 0.100 \\
\hline Vertical jump & 0.100 & 0.100 \\
\hline Carioca drill & 0.10 & 0.10 \\
\hline Trunk stability push up & 0.100 & 0.100 \\
\hline Timed sit up & 0.20 & 0.10 \\
\hline Supine bridge & 0.30 & 0.20 \\
\hline Shoulder mobility & 0.70 & 0.80 \\
\hline Active knee extension & 0.40 & 0.80 \\
\hline Four square step & 0.10 & 0.30 \\
\hline Endurance of lateral flexors & 0.30 & 0.20 \\
\hline Single leg landing & 0.80 & 0.100 \\
\hline Active straight leg raise & 0.100 & 0.100 \\
\hline Triple jump for distance & 0.70 & 0.80 \\
\hline Backward overhead medicine ball throw & 0.70 & 0.80 \\
\hline Sidearm medicine ball throw & 0.70 & 0.80 \\
\hline Closed kinetic chain upper extremity & 0.80 & 0.100 \\
\hline T test & 0.30 & 0.50 \\
\hline Illinois & 0.20 & 0.50 \\
\hline Zigzag run & 0.20 & 0.50 \\
\hline Jump squat & 0.70 & 0.80 \\
\hline Lumbar erector spinae assessment & 0.70 & 0.80 \\
\hline Quadratus lumbarum assessment & 0.80 & 0.100 \\
\hline Thomas test & 0.80 & 0.100 \\
\hline Pectoralis major assessment & 0.30 & 0.80 \\
\hline Pectoralis minor assessment & 0.30 & 0.80 \\
\hline Latissimus dorsi assessment & 0.40 & 0.50 \\
\hline Arm span & 0.30 & 0.70 \\
\hline Arm reach & 0.40 & 0.70 \\
\hline
\end{tabular}


Table 3. Frequency distribution of volleyball players by gender, dominant foot, dominant hand, level of competition, injury history and position

\begin{tabular}{|c|c|c|c|}
\hline Variable & Type & Frequency & $\%$ \\
\hline & Man & 184 & 84.8 \\
\hline \multicolumn{4}{|l|}{ Gender } \\
\hline & Woman & 33 & 15.2 \\
\hline \multirow{3}{*}{ Dominant foot } & Right & 188 & 86.6 \\
\hline & & & \\
\hline & Left & 29 & 13.4 \\
\hline \multirow{3}{*}{ Dominant hand } & Right & 189 & 78.1 \\
\hline & & & \\
\hline & Left & 28 & 12.9 \\
\hline \multirow{3}{*}{ Level of competition } & State & 58 & 26.7 \\
\hline & National & 137 & 63.1 \\
\hline & International & 22 & 10.1 \\
\hline \multirow{3}{*}{ Injury history } & Yes & 201 & 92.6 \\
\hline & & & \\
\hline & No & 16 & 7.4 \\
\hline \multirow{5}{*}{ Position } & Attacker & 72 & 33.2 \\
\hline & Center & 43 & 19.8 \\
\hline & Setter & 39 & 18.0 \\
\hline & Spiker & 42 & 19.4 \\
\hline & Libero & 21 & 9.7 \\
\hline
\end{tabular}

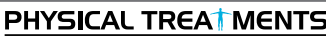

it was evaluated using the confirmatory factor analysis and fitness indices of the structure model. Based on the results of the goodness of fit test, Chi-square test was first evaluated $\left[\mathrm{P}<0.001, \chi^{2}(49, \mathrm{~N}=217)=88.023\right]$. So in order to evaluate the fitting of the model, the indices of $\mathrm{PCFI}=0.720, \mathrm{CMIN} / \mathrm{DF}=1.796, \mathrm{RMSEA}=0.061$, $\mathrm{PNFI}=0.694, \mathrm{AGFI}=0.901$ were evaluated. All indices confirmed the good fitness for the final model.

\section{Convergent and divergent validity}

Average Variances Extracted (AVE) of all the factors were greater than 0.5 and also AVE of each factor was greater than the Average Shared Square Variance (ASV) and the Maximum Shared Squared Variance (MSV). The results show that the screening tool construct of functional movements in volleyball has an appropriate convergent and divergent validity (Table 5).

\section{Reliability}

Firstly, the external consistency of the tool was estimated using the test-retest method (95\%CI: 0.44-0.96, $\mathrm{P}<0.001, \mathrm{ICC}=0.88$ ). Then, by monitoring of the error of measurement, the absolute stability was estimated to be \pm 0.77 . Construct stability and McDonald's Omega were evaluated greater than 0.7 .

\section{Discussion}

To develop the tool, a questionnaire with 82 tests was designed with six classes of functional, agility, anaerobic, aerobic, muscle length and anthropometric based on the available literature in this field. The results of the interview with volleyball experts led to the extraction of 38 tests in accordance with Table 3 . At this phase, all experts agreed that aerobic testing did not qualify for the tool. One of the features of the tool is that it is inexpensive, simple, and generalizable at wider scales, both in 
Table 4. Exploratory factor analysis of construct validity questionnaire

\begin{tabular}{|c|c|c|c|c|c|}
\hline Factor & Item & Loading & Communalities & $\%$ of Variance & Eigenvalue \\
\hline \multirow{5}{*}{ First } & 4. Inline lunge & 0.893 & 0.803 & \multirow{5}{*}{17.01} & \multirow{5}{*}{4.097} \\
\hline & 5. Lateral lunge & 0.876 & 0.772 & & \\
\hline & 6. Rotary stability & 0.766 & 0.585 & & \\
\hline & 1. Deep squat & 0.686 & 0.479 & & \\
\hline & 3. Hexagon & 0.650 & 0.431 & & \\
\hline \multirow{5}{*}{ Second } & 14. Sidearm medicine ball throw & 0.812 & 0.736 & \multirow{5}{*}{14.48} & \multirow{5}{*}{2.952} \\
\hline & 12. Closed kinetic chain upper extremity & 0.677 & 0.775 & & \\
\hline & & & & & \\
\hline & 16. Jump squat & 0.747 & 0.530 & & \\
\hline & 15. Triple jump for distance & 0.451 & 0.190 & & \\
\hline \multirow{3}{*}{ Third } & 9. Shoulder mobility & 0.961 & 0.879 & \multirow{3}{*}{14.42} & \multirow{3}{*}{1.163} \\
\hline & 8. Trunk stability push up & 0.867 & 0.739 & & \\
\hline & 2. Triple hop for distance & 0.326 & 0.289 & & \\
\hline
\end{tabular}

PHYSICAL TREA $\$ MENTS

laboratory environments and in field environments, and not time-consuming [7].

According to the experts, aerobic tests are time-consuming and exhaust subjects, and this fatigue may affect the outcome of the tool. In addition, aerobic activity can itself be an indirect risk factor for injury. In other words, fatigue resulting from aerobic activity may result in injury to the athlete. Then, after initial design of the questionnaire with 38 items, the researcher assessed its validity and reliability. Finally, 12 tests were extracted to be placed on the tools, all of which, except for squat jump - which is considered as an anaerobic test - were in the class of functional tests. Of these 12 tests, five tests of deep squat, inline lunge, shoulder mobility, trunk stability pushup, and rotary stability were common with FMS designed by Cook.

Other seven tests included lateral lunge, hexagon, sidearm medicine ball throw, upper extremity closed kinetic chain, jump squat, triple jump for distance and triple hop for distance. The choice of these tests was based on their similarity with the existing patterns of movement in volleyball and anatomical areas that are prone to injury in this sport. The results indicated the suitability of the validity and reliability of the whole tool, and stated that items are identical when measuring the same concept and structure and there is no conceptual dispersion in it.

The results showed that the reliability of this questionnaire is acceptable. The internal stability of the tool was obtained at a time interval of 2 weeks $(\mathrm{ICC}=0.88)$, which indicates that the reliability of the retest is satisfactory for the questionnaire. These results were consistent with the results of Frohm et al. (2010). They tested the reliability of a set of 9 tests in soccer players. The reliability was examined by test-retest method on 26 elite soccer players within a week interval. ICC were reported to be 0.80 and 0.81 , respectively, indicating a desirable reliability of the test set [32].

Table 5. Convergent and divergent validity of the questionnaire

\begin{tabular}{ccccc}
\hline Factor & AVS & MSV & AVE & CR \\
\hline First & 0.033 & 0.063 & 0.633 & 0.894 \\
Second & 0.174 & 0.343 & 0.513 & 0.795 \\
Third & 0.203 & 0.343 & 0.620 & 0.822 \\
\hline
\end{tabular}




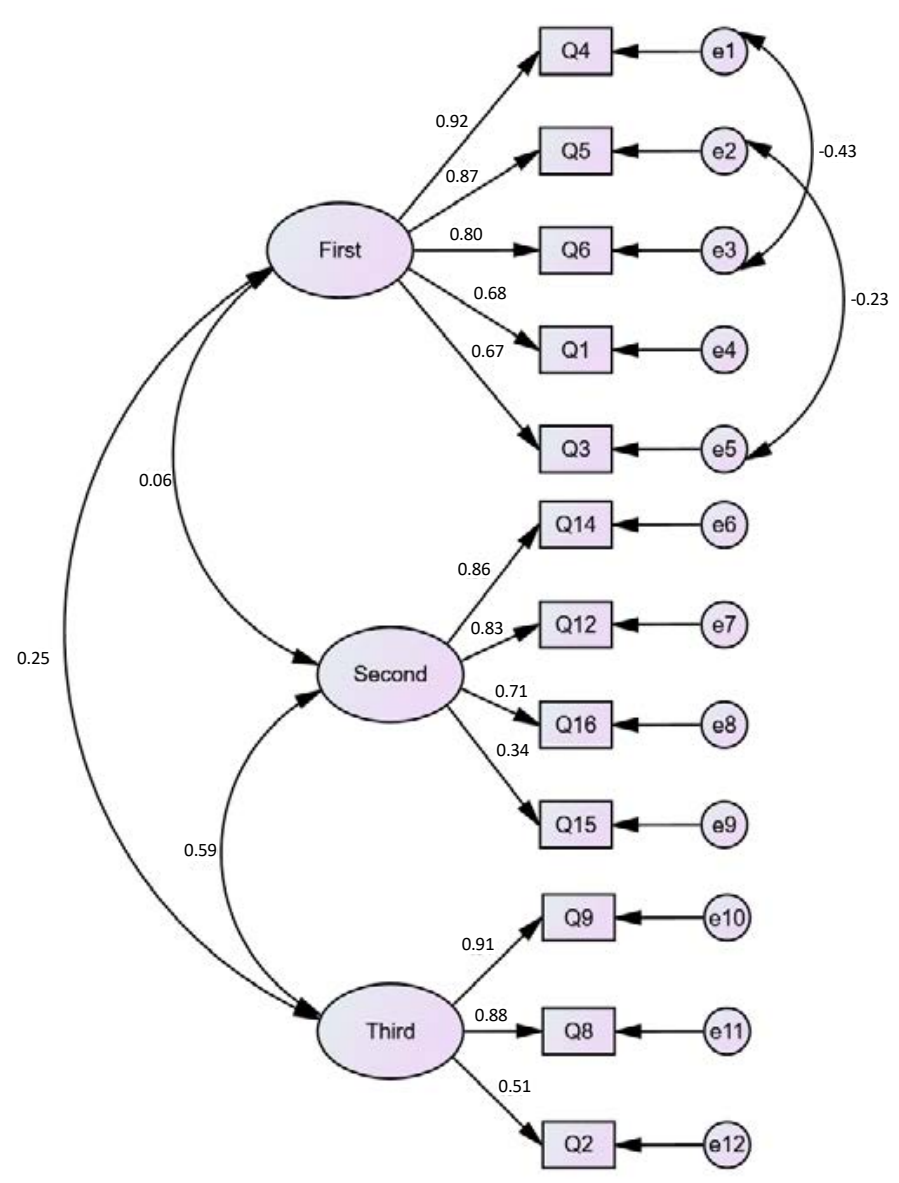

PHYSICAL TREA $\mid$ MENTS

Figure 1. The final structure of the questionnaire for the functional movement screening tool in volleyball

The results of the exploratory factor analysis in Table 5 showed that the screening factor structure of functional movements in volleyball is multidimensional. Koehle et al. (2016) in their study of the FMS factor structure by using the EFA and CFA in adults extracted two hidden factors, including a major factor consisting of shoulder mobility and active straight leg raise and a complex movement consisting of deep squats, lateral lunge and trunk stability pushup. The rotary stability of both factors was in the confirmatory factor analysis and its withdrawal from the factor structure model had little effect. The findings of this study desirably reflected the FMS functional structure [33].

In the present study, using the main factors analysis and the varimax rotation, three factors with a value higher than 1 were extracted that explained $45.91 \%$ of the total variance (Figure 1). The most loading belonged to the third factor and the least to the second factor. The first factor consisted of inline lunge, lateral lunge, rotary stability, deep squat and hexagon. Inline lunge and lateral lunge had the most loading and the strongest correlation. The movement pattern of these two tests is similar to the movement pattern "get by the forearms" of liberos. Any functional movement impairment such as valgus or varus in the knee may lead to a compensatory movement pattern and, in the long run, may expose the athlete to injuries such as anterior cruciate ligament rupture.

Biomechanical studies indicate an increase in the probability of occurrence of jumpers' knee between the players with the highest jumps. This is more likely to occur during the landing of spikes, which is associated with an increase in the angle of flexion of the knee. Other studies have examined the factors associated with jump technique and studied other biomechanical factors that may provide the basis for jumpers knee [18]. Knee injuries with a prevalence rate of $15.2 \%$ of the total number of injuries associated with volleyball after ankle sprain with $25.9 \%$ of the injuries, have the highest rate of injury leading to the being away from competitions among the volleyball players [12]. 
However, distribution of injury in volleyball has a strong dispersion in various studies. This issue is mainly related to the injury record method and the researcher's definition of injury. In addition, some studies have been conducted generally and have taken both types of acute and overuse injury into consideration [34]. The second factor consisted of sidearm medicine ball throw, upper extremity closed kinetic chain, jump squat, and triple jump for distance. The sidearm medicine ball throw and upper extremity closed kinetic chain had the highest loading, and therefore were strongly correlated. The emphasis of the experts on these tests indicates the importance of the upper extremity in this sport.

In volleyball, it is very important for the athlete to have proper receives on both sides. Any shortness in contraction tissue on one side of the upper extremity, in comparison to the other, may affect the proper receives on the shorter side. Experts say that these two tests can detect any asymmetry or limitation of upper extremity that cause functional impairment and, in the long run, exposes the athlete to shoulder joint injury. Shoulder joint injuries, which are in the class of prolonged injuries, have the highest incidence in volleyball after ankle and knee injuries [35].

The third factor consists of the shoulder mobility, trunk stability pushup and triple hop for distance. According to the literature, the shoulder joint is always vulnerable to injury in volleyball. According to Reeser et al. (2006), a professional volleyball player in each season hits more than 40000 spikes. Although the load and the kinetic energy exerted by a spike is unknown, it can be clearly stated that the huge volume of spikes and the need for dynamic stability, exerts a lot of pressure to the volleyball player shoulder [35].

The shoulder joint is exposed to intense pressure during the playing of volleyball, and any discomfort in the shoulders affects the technique of the game. For this reason, there is a greater need for medical care in the trauma of the shoulder. The importance of the stability and mobility of this joint in volleyball should always be taken into consideration by physicians, physiotherapists and athletes. The shoulder joint mobility test can detect any asymmetry and functional impairment associated with this joint. This movement pattern reflects the natural rhythm of the chest scapula spine, chest spine, and chest during interacting movements of the shoulder and upper extremity.

However, Peter et al. (2014) who investigated the relationship between the total rotary movement range of the glenohumeral joint and the score of the shoulder mobility test in overhead sports, acknowledged that the rotary range of movement of the glenohumeral joint was only one of several components effective on the implementation of the shoulder mobility test and it cannot alone determine the outcome of this test. They concluded that the shoulder joint mobility test should not be used alone to determine significant clinical differences in athletes in overhead sports, and complementary tests are necessary [36]. Trunk stability pushup tests the ability to fix the spine on sagittal plane in the closed kinetic chain and the movement of asymmetric pushing of the upper extremity. By placing an athlete in a state of instability, this movement pattern tries to challenge the stability of the trunk and upper extremity [14].

Unlike previous studies, this study examined factor structure using exploratory and confirmatory analysis, while in previous studies, these tools were explored solely by exploratory factor analysis [37]. In contrast to exploratory factor analysis, confirmatory factor analysis can examine the goodness of fitting of the results of the proposed factor structure, which provides a more precise and deterministic evaluation of latent variables or structures.

In this study, after the elimination of all weak markers and outliers, as well as the examination of the normality of the data and adaptation to the structures obtained in the exploratory factor analysis, and also ensuring the identifiability of the model, the evaluation of goodness of fitting of the model was done. According to various indices reported, model fitting was evaluated appropriately. The PCFI index, which is a sample-size sensitive indicator [38], also evaluates a good fitting of the model. The final model of factor analysis showed that all standardized loading, with the exception of two cases, are above 0.5 , which had the lowest acceptable loading. Therefore, according to the results of this model as well as the results of confirmatory factor analysis, the observed indices are confirmed and all fitness indices have a desirable standard level.

In this study, appropriate psychometric properties and correction of factor structure of the questionnaire was approved. In total, the face validity, content validity, and structure validity of the tool were approved by experts and volleyball players. Tool reliability was confirmed as well after the tests was reduced from 38 tests to 12 . In the future, by determining the normative value for the tests and identifying a cutoff point, it is possible to test the reliability of the injury predicting tool by performing the tests. Further research is needed in the future to use this tool as an interventional tool in volleyball. Future and follow-up 
research at various volleyball players will show how well this tool can predict the injury to these players.

\section{Ethical Considerations}

\section{Compliance with ethical guidelines}

The sampling was carried out after receiving approval from local Ethics Committee and a referral from the Guilan University of Medical Sciences (Code of ethics: IR.GUMS.REC.1396.517) to enter the research setting. The ethical principles of seeking informed agreement from participants and ensuring the confidentiality of their personal information were followed. The location and date of the interviews were determined based on the participants' agreement.

\section{Funding}

This research has also supervised by Iranian Volleyball Federation. This study is part of the $\mathrm{PhD}$ thesis of the first author of the article which was conducted at the Faculty of Physical Education, University of Guilan.

\section{Conflict of interest}

The authors declared no conflict of interest.

\section{Acknowledgments}

The authors of the article would like to express their deep appreciation to the Volleyball Federation Education Committee, which showed their full cooperation in conducting this study, as well as the participants who shared their scientific experiences.

\section{References}

[1] Dorrel BS, Long T, Shaffer S, Myer GD. Evaluation of the functional movement screen as an injury prediction tool among active adult populations: A systematic review and meta-analysis. Sports Health. 2015; 7(6):532-7. [DOI:10.1177/1941738115607445] [PMID] [PMCID]

[2] Junge A, Langevoort G, Pipe A, Peytavin A, Wong $\mathrm{F}$, Mountjoy $\mathrm{M}$, et al. Injuries in team sport tournaments during the 2004 Olympic Games. The American Journal of Sports Medicine. 2006; 34(4):565-76. [DOI:10.1177/0363546505281807] [PMID]

[3] Schneiders AG, Davidsson Å, Hörman E, Sullivan SJ. Functional movement screen ${ }^{\mathrm{TM}}$ normative values in a young, active population. International Journal of Sports Physical Therapy. 2011; 6(2):75-82. [PMID] [PMCID]
[4] Whatman C, Hing W, Hume P. Physiotherapist agreement when visually rating movement quality during lower extremity functional screening tests. Physical Therapy in Sport. 2012; 13(2):87-96. [DOI:10.1016/j.ptsp.2011.07.001]

[5] Mottram S, Comerford M. A new perspective on risk assessment. Physical Therapy in Sport. 2008; 9(1):40-51. [DOI:10.1016/j.ptsp.2007.11.003] [PMID]

[6] Carek PJ, Mainous A. The preparticipation physical examination for athletics: A systematic review of current recommendations. BMJ. 2003; 327(7418):E170-3.

[7] Dallinga JM, Benjaminse A, Lemmink KA. Which screening tools can predict injury to the lower extremities in team sports?. Sports Medicine. 2012; 42(9):791-815. [DOI:10.1007/ BF03262295] [PMID]

[8] Morehead EK. Development of a functional movement screening tool for football [PhD dissertation]. Preston: University of Central Lancashire; 2014.

[9] Sleeper MD, Kenyon LK, Casey E. Measuring fitness in female gymnasts: The gymnastics functional measurement tool. International Journal of Sports Physical Therapy. 2012; 7(2):124-33. [PMID] [PMCID]

[10] Gabbe BJ, Finch CF, Wajswelner H, Bennell KL. Predictors of lower extremity injuries at the community level of Australian football. Clinical Journal of Sport Medicine. 2004; 14(2):56-63. [DOI:10.1097/00042752-200403000-00002] [PMID]

[11] Steinberg N, Hershkovitz I, Peleg S, Dar G, Masharawi Y, Heim $M$, et al. Range of joint movement in female dancers and nondancers aged 8 to 16 years: anatomical and clinical implications. The American Journal of Sports Medicine. 2006; 34(5):814-23. [DOI:10.1177/0363546505281805] [PMID]

[12] Bere T, Kruczynski J, Veintimilla N, Hamu Y, Bahr R. Injury risk is low among world-class volleyball players: 4-year data from the FIVB Injury Surveillance System. British Journal of Sports Medicine. 2015; 49(17):1132-7. [DOI:10.1136/bjsports-2015-094959]

[13] Augustsson SR, Augustsson J, Thomee R, Svantesson U. Injuries and preventive actions in elite Swedish volleyball. Scandinavian Journal of Medicine \& Science in Sports. 2006 16(6):433-40. [DOI:10.1111/j.1600-0838.2005.00517.x] [PMID]

[14] Cook G, Burton L, Hoogenboom BJ, Voight M. Functional movement screening: The use of fundamental movements as an assessment of function-part 1. International Journal of Sports Physical Therapy. 2014; 9(3):396-409. [PMID] [PMCID]

[15] Bishop C. Movement screening: An integrated approach to assessing movement quality. In: Turner A, Comfort $\mathrm{P}$, editor. Advanced Strength and Conditioning: An Evidencebased Approach. Abingdon: Routledge; 2017.

[16] Parchmann CJ, McBride JM. Relationship between functional movement screen and athletic performance. The Journal of Strength \& Conditioning Research. 2011; 25(12):337884. [DOI:10.1519/JSC.0b013e318238e916] [PMID]

[17] Rosch D, Hodgson R, Peterson L, Graf-Baumann T, Junge A, Chomiak J, et al. Assessment and evaluation of football performance. The American Journal of Sports Medicine. 2000; 28(5_suppl):29-39. [DOI:10.1177/28.suppl_5.s-29]

[18] Bisseling RW, Hof AL, Bredeweg SW, Zwerver J, Mulder T. Are the takeoff and landing phase dynamics of the vol- 
leyball spike jump related to patellar tendinopathy?. British Journal of Sports Medicine. 2008; 42:483-9. [DOI:10.1136/ bjsm.2007.044057] [PMID]

[19] Parenteau-G E, Gaudreault N, Chambers S, Boisvert C, Grenier A, Gagné G, et al. Functional movement screen test: A reliable screening test for young elite ice hockey players. Physical Therapy in Sport. 2014; 15(3):169-75. [DOI:10.1016/j. ptsp.2013.10.001] [PMID]

[20] Gulgin H, Hoogenboom B. The Functional Movement Screening (FMS) ${ }^{\mathrm{TM}}$ : An inter-rater reliability study between raters of varied experience. International Journal of Sports Physical Therapy. 2014; 9(1):14-20. [PMID] [PMCID]

[21] Shultz R, Anderson SC, Matheson GO, Marcello B, Besier T. Test-retest and interrater reliability of the functional movement screen. Journal of Athletic Training. 2013; 48(3):331-6. [DOI:10.4085/1062-6050-48.2.11] [PMID] [PMCID]

[22] Corbin J, Strauss A, Strauss AL. Basics of qualitative research. Thousand Oaks, California: Sage; 2014.

[23] Mohammadbeigi A, Mohammadsalehi N, Aligol M. [Validity and reliability of the instruments and types of measurments in health applied researches (Persian)]. Journal of Rafsanjan University of Medical Sciences. 2015; 13(12):1153-70.

[24] Dempsey PA, Dempsey AD. Using nursing research: Process, critical evaluation, and utilization. Philadelphia: Lippincott Williams \& Wilkins; 2000.

[25] Meyers LS, Gamst G, Guarino AJ. Applied multivariate research: Design and interpretation. Thousand Oaks, California: Sage; 2016.

[26] Jaccard J, Wan CK, Jaccard J. LISREL approaches to interaction effects in multiple regression. Thousand Oaks, California: Sage; 1996.

[27] Munro BH. Statistical methods for health care research. Philadelphia: Lippincott Williams \& Wilkins; 2005.

[28] Schreiber JB, Nora A, Stage FK, Barlow EA, King J. Reporting structural equation modeling and confirmatory factor analysis results: A review. The Journal of Educational Research. 2006; 99(6):323-38.[DOI:10.3200/JOER.99.6.323-338]

[29] Esposito Vinzi V, Chin WW, Henseler J, Wang H. Handbook of partial least squares: Concepts, methods and applications. Berlin: Springer; 2010. [DOI:10.1007/978-3-540-32827-8]

[30] Hooper D, Coughlan J, Mullen M. Structural equation modelling: Guidelines for determining model fit. Electronic Journal on Business Research Methods. 2007; 6(1):53-60.

[31] Lawshe $\mathrm{CH}$. A quantitative approach to content validity 1. Personnel Psychology. 1975; 28(4):563-75. [DOI:10.1111/j.1744-6570.1975.tb01393.x]

[32] Frohm A, Heijne A, Kowalski J, Svensson P, Myklebust G. A nine-test screening battery for athletes: A reliability study. Scandinavian Journal of Medicine \& Science in Sports. 2012; 22(3):306-15. [DOI:10.1111/j.1600-0838.2010.01267.x] [PMID]

[33] Koehle MS, Saffer BY, Sinnen NM, MacInnis MJ. Factor structure and internal validity of the functional movement screen in adults. The Journal of Strength \& Conditioning Research. 2016; 30(2):540-6. [DOI:10.1519/ JSC.0000000000001092] [PMID]
[34] Verhagen EA, Van der Beek AJ, Bouter LM, Bahr RM, Van Mechelen W. A one season prospective cohort study of volleyball injuries. British Journal of Sports Medicine. 2004; 38(4):47781. [DOI:10.1136/bjsm.2003.005785] [PMID] [PMCID]

[35] Reeser JC, Verhagen EA, Briner WW, Askeland TI, Bahr R. Strategies for the prevention of volleyball related injuries. British Journal of Sports Medicine. 2006; 40(7):594-600. [DOI:10.1136/bjsm.2005.018234] [PMID] [PMCID]

[36] Sprague PA, Mokha GM, Gatens DR, Rodriguez Jr R. The relationship between glenohumeral joint total rotational range of motion and the functional movement screen ${ }^{\mathrm{TM}}$ shoulder mobility test. International Journal of Sports Physical Therapy. 2014; 9(5):657-64. [PMID] [PMCID]

[37] Vieira RX, Pechorro P, Diniz A. T08-P-10 validation of Index of Sexual Satisfaction (ISS) for use with Portuguese women. Sexologies. 2008; 17(1):S115. [DOI:10.1016/S11581360(08)72833-0]

[38] Brouwers A, Tomic W, Stijnen S. A confirmatory factor analysis of scores on the teacher efficacy scale. Swiss Journal of Psychology. 2002; 61(4):211-9. [DOI:10.1024/1421-0185.61.4.211] 